International Journal of Applied Dental Sciences 2021; 7(4): 262-263

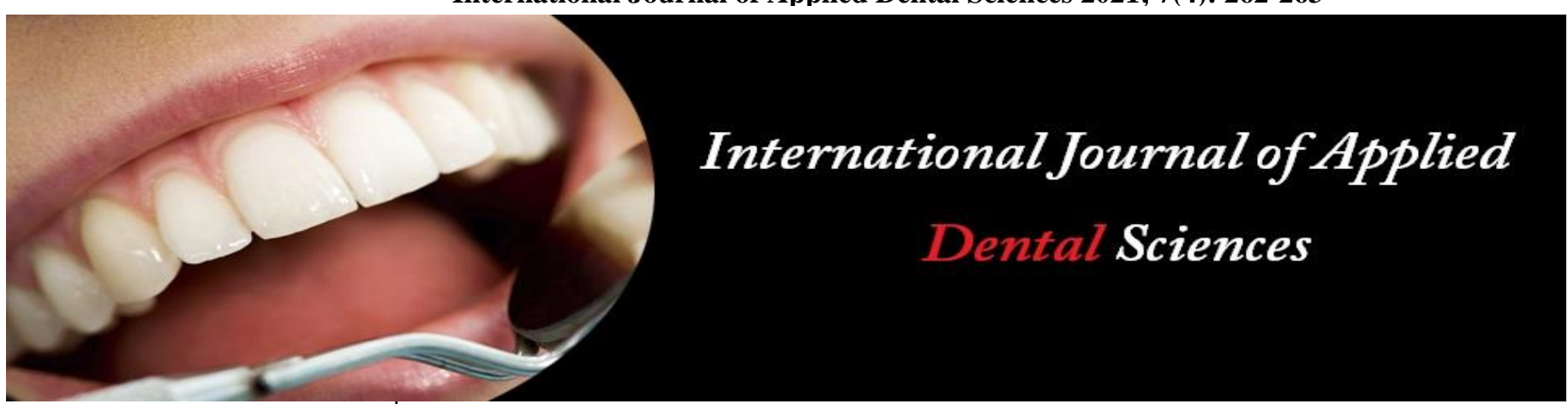

ISSN Print: 2394-7489

ISSN Online: 2394-7497

IJADS 2021; 7(4): 262-263

(C) 2021 IJADS

www.oraljournal.com

Received: 26-08-2021

Accepted: 29-09-2021

Dr. Neha Singh

Post Graduate Student,

Department of Conservative

Dentistry and Endodontics,

Rama Dental College, Hospital

And Research Center, Kanpur,

Uttar Pradesh, India

Dr. Sharad sharma

Post Graduate Student,

Department of Conservative

Dentistry and Endodontics,

Rama Dental College, Hospita

and Research Center, Kanpur,

Uttar Pradesh, India
Corresponding Author:

Dr. Neha Singh

Post Graduate Student:

Department of Conservative

Dentistry and Endodontics,

Rama Dental College, Hospital

And Research Center, Kanpur,

Uttar Pradesh, India

\section{Mandibular incisor with two canals: A case report}

\author{
Dr. Neha Singh and Dr. Sharad Sharma
}

DOI: $\underline{\text { https://doi.org/10.22271/oral.2021.v7.i4d.1382 }}$

\section{Abstract}

The root canal system of mandibular incisors often have three pulp horns and a single root canal, but it has also been demonstrated that there is presence of bifurcated and lateral canals also. The bifurcation of a root canal is the position at which a single canal separates into two smaller canals that follow divergent pathways, in some cases, the canals may re-join to form a single canal again.

Keywords: Endodontic treatment, canal configuration, bifurcation

\section{Introduction}

For a successful endodontic therapy, thorough knowledge of root canal morphology along with its variation is mandatory [1]. The root canal system of mandibular incisors often have three pulp horns and a single root canal, but it is also been demonstrated that there is presence of bifurcated and lateral canals also. The bifurcation of a root canal is the position at which a single canal separates into two smaller canals that follow divergent pathways; but in some cases, the canals may rejoin to form a single canal again ${ }^{[2]}$. Lateral canals are canals which emanate from the main canal and take a perpendicular course which exit into the periodontal ligament space ${ }^{[3]}$. As reported, more than $40 \%$ of mandibular incisors show the presence of two canals and teeth more than $1 \%$ has two separate apical foramina ${ }^{[2,4]}$. Despite the low prevalence, clinicians should take into consideration the possible variations in the number of roots and root canals of mandibular incisors.

However, variations such as presence of extra canal in mandibular incisors are documented by various researchers previously. Canal configuration of mandibular incisors was classified by Vertucci into four types in $1974^{[5]}$.

- Type I: Single canal continues from the pulp chamber to the apex.

- Type II: Two separate canals leave the pulp chamber, but join and form one canal short of the apex.

- Type III: Single canal leaves the pulp chamber, but it divides into two within the body of the root and merges again to exist as one canal.

- Type IV: Two separate and distinct canals are present from the pulp chamber to apex.

Failure by the operator to recognise the anatomy of a root canal system and the possible developmental anomalies may lead to inadequate cleaning and shaping of the root canal system, which in turn may contribute to failure of endodontic treatment and lead to need for endodontic retreatment ${ }^{[2]}$. This case report describes the occurrence of 2 separate canals which end in single apical foramina in all mandibular incisors of the patient.

\section{Case Report}

A female patient, 35year old came to the Department of Conservative Dentistry and Endodontics, Rama dental college, Kanpur with the chief complaints of pain with lower front region since a month. The medical history was non-contributory. The clinical examination revealed pain on percussion and no response was seen to thermal and electrical pulp sensitivity tests on both lower lateral incisors. Widening of periodontal ligament space was seen in the pre-operative radiograph. A pre-operative radiograph showed presence of two canals in right mandibular central incisor (41) (Figure 1). 


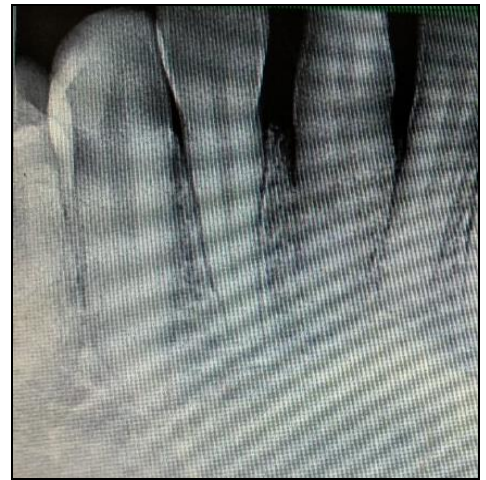

Fig 1: Pre-operative Radiograph i.r.t 41

At the first appointment, access opening was prepared on the mandibular central incisors. The pulp chamber was noted as to have a large size and a second root canal orifice was found in the lingual portion of the pulp chamber after widening the access cavity bucco-lingually in the tooth.

The patency was confirmed using a no. $10 \mathrm{k}$ file. Working length determination was done by using a 10 . no. $\mathrm{K}$ file in the buccal canal \& 15 no. K file in the lingual canal. (Figure 2)

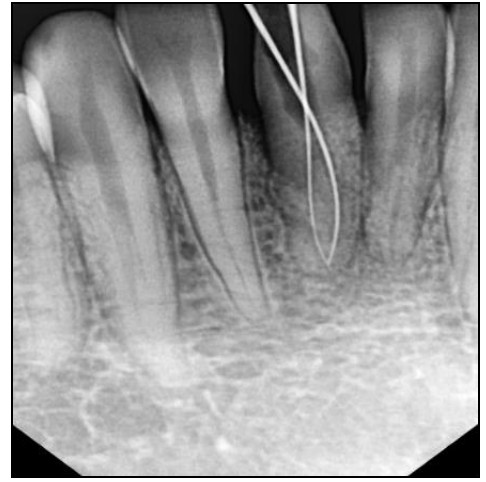

Fig 2: Radiograph showing working length i.r.t. 41

Biomechanical preparation was done using step back technique. $2.5 \%$ of sodium hypochlorite and $17 \%$ EDTA were used for simultaneous irrigation. The canals were thoroughly rinsed with normal saline after each instrument. The canals were dried with absorbent points and the canals were obturated using lateral condensation and were coated with zinc oxide eugenol-based sealer and placed in the canals and sealed (Figure 3 ) and the tooth was subsequently restored.

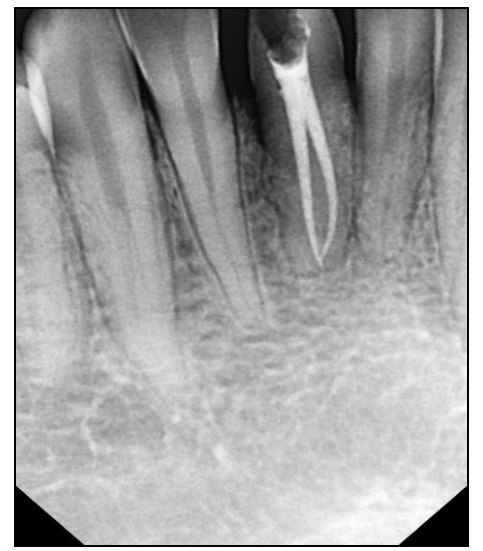

Fig 3: Radiograph showing obturation i.r.t.41

\section{Discussion}

The main objective of root canal treatment is thorough debridement of the entire pulp space and complete obturation with an inert material ${ }^{[6]}$. If there is sudden change in the canal radio density, narrowing of the canal space, abrupt disappearance of canal space during interpretation of diagnostic radiographs gives a clue for the need of one extra angulated radiograph to diagnose an extra root or canal ${ }^{[7]}$. A well-designed access preparation is essential for a good post treatment result. Without adequate access to the canals and the apex, instruments and materials are difficult to handle in the highly complex and variable root canal system. Appropriate access cavity preparation provides straight line access to the apical foramina which will aid in locating all root canal orifices and it also conserves sound tooth structure [8].

Because of the small size and internal anatomy, mandibular incisors may be one of the most difficult access cavities to prepare. These teeth usually have two canals that are buccolingually oriented amongst which the lingual canal is most often missed. To avoid missing the canal, the clinician should extend the access cavity preparation well into cingulum gingivally, which, if present, is located directly beneath it. ${ }^{8}$ When there are two canals, the buccal canal is the easiest to locate and is usually straighter than the canal lingually, which is usually shielded by lingual shelf ${ }^{[9]}$.

\section{Conclusion}

The morphology of the pulp chamber in lower incisors can often have deviations in the number and the configuration of root canals. For successful endodontic treatment it is important for a clinician to have thorough knowledge of the anatomy of the teeth, should perform additional radiographs in different angulations and modify the cavity for endodontic access, which would facilitate the procedure of locating additional root canals.

\section{References}

1. Ingle JI. Endodontics. In: 3rd ed. Lea \& Febiger, Philadelphia: Saunders 1985, 102.

2. Kabak YS, Abbott PV. Endodontic treatment of mandibular incisors with two root canals: report of two cases. Aust Endod J 2007;33:27-31. https://doi.org/10.1111/j.1747- 4477.2007.00054.x

3. Carrotte P. Endodontics: part 4. Morphology of the root canal system. $\mathrm{Br}$ Dent J 2004;197:379-83; https://doi.org/10.1038/sj.bdj.4811711

4. Saraswathi FK, Toran S, Kumar P. Supplemental Rudimentary Tuberculates with Unusual Morphology: A Case Report. Int J Dent Clinics 2010;2:42-7.

5. Vertucci FJ. Root canal anatomy of the mandibular anterior teeth. J Am Dent Assoc 1974;89:369-71.

6. Christie WH, Peikoff MD, Acheson DW. Endodontic treatment of two maxillary lateral incisors with anomalous root formation. J Endod 1981;7:528-34. https://doi.org/10.1016/S0099- 2399(81)80116-1

7. Victorino FR, Bernardes RA, Baldi JV, Moraes IG, Bernardinelli N, Garcia RB et al. Bilateral mandibular canines with two roots and two separate canals: Case report. Braz Dent J 2009;20:84-6. https://doi.org/10.1590/S0103 64402009000100015

8. Cohen S, Hargreaves K. Pathways of the Pulp, Elsevier Mosby, 9th edition 2006.

9. Shaikh MA, Kalhoro FA, Sangi L. Frequency of second canal in mandibular lateral incisors in vitro. Pakistan Oral \& Dental Journal 2014;34:147-9. 